\title{
CONTROL BIOLÓGICO DEL "cogollero del maíz" Spodoptera frugiperda, (Lepidoptera; Noctuidae) CON EL BACULOVIRUS SFVPN, EN IQUITOS-PERU
}

\author{
Joel Vásquez ${ }^{1}$, Zeddam J. L. ${ }^{2}$, Tresierra A. A. ${ }^{3}$
}

\section{RESUMEN}

Con el propósito de encontrar una alternativa al control químico del "cogollero del maíz” Spodoptera frugiperda, principal plaga para el cultivo del maíz (Zea mays), se estudió la posibilidad de utilizar como controlador biológico de esta plaga, al baculovirus SfVPN (Virus de Poliedrosis Nuclear de Spodoptera frugiperda). Utilizando larvas del $3^{\text {er }}$ estadío se comprobó que es un eficiente controlador biológico, determinándose que la dosis letal media fue de 49,653 cuerpos de inclusión (CI)/ larva, con un promedio de tiempo letal medio $\left(\mathrm{TL}_{50}\right)$ de $6.5 \pm 0.5$ días. Asímismo, el número de CI del SfVPN producidos por una larva de $5^{\text {to }}$ estadío fue de $5.4 \mathrm{X} 10^{8} \mathrm{CI} /$ larva, y de $6^{\text {to }}$ estadío fue de $7.3 \times 10^{8} \mathrm{CI} /$ larva, constituyéndose estos estadíos en buenas productoras de virus para formulaciones de insecticidas biológicos. Se propone, por tanto, el empleo del SfVPN como una buena alternativa para el control de Spodoptera frugiperda.

Palabras Claves: Control biológico, Baculovirus-SfVPN, cogollero del maíz, Spodoptera frugiperda, Zea mays, cuerpos de inclusión, larvas.

\begin{abstract}
In order to identify an alternative to chemical control of "fall armyworm" Spodoptera frugiperda, the principal pest of corn crops (Zea mays), baculovirus SfNPV (Spodoptera frugiperda nuclear poliedrosis virus) was examined as a possible biological control agent. After infection of $3^{\text {rd }}$ instar larvae, it was determined that the mean Lethal Dose $\left(\mathrm{DL}_{50}\right)$ was 49,653 inclusion bodies (IB)/larvae and the mean time before death of $50 \%$ the larvae $\left(\mathrm{TL}_{50}\right)$ was $6.5 \pm 0.5$ days. Surviving $5^{\text {th }}$ instar larvae

1 Biólogo. Instituto de Investigaciones de la Amazonía Peruana. IIAP/PBIO Apartado 784, Iquitos, Peru. E-mail: pbio@iiap.org.pe

2 Doctor en Virología. Instituto de Investigaciones para el Desarrollo (IRD-Francia) E-mail: jzeddam@yahoo.com

3 Microbiólogo, M.Sc. Dpto. de Microbiología. Univ. Nac. de la Amazonía Peruana. (UNAP)
\end{abstract}


contained $5.4 \mathrm{X} 10^{8}(\mathrm{IB}) /$ larvae whereas surviving $6^{\text {th }}$ instar larvae contained $7.3 \times 10^{8}$ (IB)/larvae. Therefore, the employment of SfNPV is proposed as a good alternative control method of pest Spodoptera frugiperda.

Key words: Biological control, Baculovirus-SfVPN, fall armyworm, Spodoptera frugiperda, Zea mayz, Inclusion bodies, Larvae

\section{INTRODUCCIÓN}

El “maíz”, Zea mays L, es un cultivo que está diseminado en todo el ámbito nacional, ocupando el 14\% del área cultivada. Es un componente básico de la alimentación humana y animal (Valdiviezo y Nuñez, 1989).

En la región Loreto, el cultivo del maíz ocupa grandes extensiones de terreno, especialmente en las restingas bajas (Agronoticias, 1997). El principal problema fitosanitario de esta gramínea es la plaga comúnmente conocida como "cogollero del maíz" Spodoptera frugiperda (Lepidoptera; Noctuidae). Esta plaga ocurre en toda la etapa del crecimiento inicial de la planta, y puede reducir la producción hasta en $40 \%$ (Herrera, 1979).

El método de control comúnmente utilizado es el uso de sustancias químicas, las cuales desequilibran el ecosistema, destruyen los organismos benéficos y permiten que la plaga desarrolle poblaciones resistentes a los insecticidas (Valicente y Cruz, 1991). El Servicio Nacional de Sanidad Agraria de la Región San Martín (SENASASM) detectó, en 1997, en la provincia de San Martín, la presencia de un microorganismo benéfico catalogado por J. L. Zeddam como un baculovirus (Virus de Poliedrosis Nuclear-SfVPN), el cual podría ser capaz de matar al "cogollero del maíz" Spodoptera frugiperda, sin ocasionar daño alguno a los insectos benéficos. No es tóxico para el hombre ni contamina el medio ambiente (Agronoticias, 1997).

Los objetivos planteados en el estudio son los siguientes:

- Evaluar el baculovirus SfVPN (Virus de Poliedrosis Nuclear) como controlador biológico del cogollero del maíz

- Determinar la Dosis Letal Medía $\left(\mathrm{DL}_{50}\right)$ del baculovirus SfVPN para larvas del $3^{\text {er }}$ estadío el cogollero del maíz.

- Determinar el Tiempo Letal Medio $\left(\mathrm{TL}_{50}\right)$ del SfVPN para larvas del $3^{\text {er }}$ estadío del cogollero del maíz.

- Determinar el número promedio de cuerpos de inclusión producidos en larvas del cogollero del maíz, (CI/larva) del $5^{\text {to }}$ y $6^{\text {to }}$ estadíos. 


\section{MATERIALES Y MÉTODOS}

El trabajo fue realizado entre julio de 1998 y agosto de 1999. La crianza masiva del cogollero del maíz se hizo en el laboratorio del Departamento de Zoología de la Universidad Nacional de la Amazonía Peruana -UNAP-, y los ensayos en el laboratorio del Instituto de Investigaciones de la Facultad de Ciencias Biológicas de la UNAP, a una temperatura promedio de $25^{\circ} \mathrm{C}$.

\section{Metodología}

\section{Procedencia e Identificación del Virus}

El virus ha sido colectado en el distrito de Tarapoto, región San Martín, y fue identificado en el Centro Internacional de la Papa (CIP), a partir de larvas de Spodoptera frugiperda infectadas por el virus. La determinación ha sido hecha en base a los cuerpos de inclusión que presentan formas poliédricas características de este grupo de virus, los cuales son fácilmente observables en un microscopio compuesto $(400 \mathrm{X})$, y fue confirmada mediante análisis del genoma viral.

\section{Crianza artificial del "cogollero del maíz" Spodoptera frugiperda}

Para la crianza se colectaron en envases de plástico 50 larvas de los últimos estadíos (entre $5^{\text {to }}$ y $6^{\text {to }}$ estadíos) de los maizales infestados en la localidad de Padrecocha (provincia de Maynas), ubicada geográficamente a $3^{\circ} 42^{\prime} 17^{\prime \prime} \mathrm{LS}$ y $73^{\circ} 17^{\prime} 23^{\prime \prime} \mathrm{LO}$, con una altitud de $78.8 \mathrm{msnm}$, con una temperatura promedio de $29^{\circ} \mathrm{C}$ y $86 \%$ de humedad relativa. En el laboratorio las larvas fueron alimentadas con hojas de "higuerilla" Ricinus comunis L., hasta el estadío de pre-pupa. Las pupas sanas se depositaron en placas petri, para luego ser colocadas dentro de la jaula de oviposición que contenía unos floreros con hojas de "grama nudillo" Brachiaria purpurescens (Raddi) Henrard, los cuales servían como sustrato de oviposición. Luego, se esperó la emergencia de los adultos.

Desde la emergencia, los adultos se alimentaron con agua azucarada al $0.05 \%$, diariamente. Los huevos se colectaron manualmente revisando cuidadosamente las hojas de los floreros. Las posturas recuperadas, se desinfectaron con hipoclorito de sodio al $0.2 \%$ para reducir la introducción de patógenos en la crianza, luego, se colocaron en placas petri y se esperó la emergencia de las larvas. 
Un grupo de larvas se destinaron al reciclaje de la plaga y otro grupo para la multiplicación del virus. La alimentación de las larvas se hizo con "higuerillas", previamente desinfectadas con hipoclorito de sodio al $0.2 \%$.

La identificación de la plaga se realizó en el Centro de Control Biológico (CCB) Ate Vitarte-Lima y en el Laboratorio de Entomología del Instituto de Investigaciones de la Amazonía Peruana-IIAP, mediante comparaciones de material y uso de claves taxonómicas del género Spodoptera (Zucchi et al., 1993. Todd y Poole, 1980).

\section{Multiplicación del baculovirus (SfVPN)}

Para multiplicar el baculovirus, se empleó una suspensión de SfVPN no purificada, ni cuantificada en la que se sumergió las hojas de higuerilla previamente desinfectadas, y se dejo secar a temperatura ambiente. Se colocaron en los envases rectangulares entre 50 a 100 larvas del $2^{\text {do }}$ y $3^{\text {er }}$ estadío, las cuales fueron alimentadas con las hojas portadoras del virus por espacio de 24 horas. Transcurrido este tiempo, las larvas se infectaron al ingerir el alimento infestado, luego se alimentó diariamente con hojas frescas sin infestar y se espero de 6 a 8 días más para la recolección de las larvas muertas, las que se colocaron en tubos de ensayo para ser almacenados a temperatura de $10{ }^{\circ} \mathrm{C}$.

\section{Purificación del SfVPN}

La purificación fue realizada en el Centro Internacional de la Papa (CIP), La MolinaLima. Para este propósito se empleó el método descrito por Alves (1986). Se utilizaron larvas muertas por el Baculovirus, y conservadas en refrigeración. En un mortero se procedió a triturar las larvas y se homogenizó con agua destilada estéril. Se filtró para separar todas las partes gruesas del insecto (cabezas y cutícula). Este material filtrado se centrifugó a 10,000 rpm durante 60 minutos, se eliminó el sobrenadante y se conservó el sedimento que contenía los cuerpos de inclusión del SfVPN para resuspenderlo; luego, se preparó tubos con gradiente de sacarosa con concentraciones de $80 \%, 60 \%$ y $45 \%$, y el sedimento viral resuspendido se agregó en los tubos de sacarosa y se centrifugó a 32,500 rpm durante 60 minutos. Pasado este tiempo, se observó diferentes bandas y se identificó una banda blanca que correspondía a la alta concentración de SfVPN, con una pipeta Pasteur se recuperó esta concentración viral y se distribuyó en tubos de centrifugación de forma proporcional para ser diluida tres a cuatro veces su volumen con agua destilada. Luego, se mezcló para uniformizar y se volvió a centrifugar a $10,000 \mathrm{rpm}$ por espacio de 60 minutos, se quitó el sobrenadante y el virus purificado quedó sedimentado, posteriormente, se coloco en microtubos con agua destilada para ser almacenados a una temperatura de $20^{\circ} \mathrm{C}$ hasta su utilización. 


\section{Determinación de la Dosis Letal Medía $\left(\mathrm{DL}_{50}\right)$ y el Tiempo Letal Medio $\left(\mathrm{TL}_{50}\right)$}

Se utilizó una suspensión purificada de SfVPN y se contaron los cuerpos de inclusión. Empleando la cámara de Neubauer se contaron los poliedros presentes en sólo cinco cuadrados secundarios de los 25 que contiene el cuadrado primario central (CPC), se sumó los poliedros de los 5 cuadrados y se multiplico por 50,000 para obtener el resultado del número de cuerpos de inclusión por centímetro cúbico. Este dato se transformo mediante el cálculo del número de poliedros en el volumen que se proporcionó a cada larva sometida a tratamiento, por lo que la dosificación fue expresada en números de cuerpos de inclusión por larva (CI/larva). Una vez determinado el número de cuerpos de inclusión en la suspensión, se prepararon las diferentes concentraciones a ensayar en la evaluación de la dosis letal medía $\left(\mathrm{DL}_{50}\right)$, las cuales se muestran en la Tabla 1. Tanto para el testigo como para las concentraciones se utilizaron 30 larvas sanas del $3^{\text {er }}$ estadío por ser de fácil manipuleo y mayor actividad, lo cuál aseguró una buena infectación.

La infectación se hizo en placas petri, en forma individual. Se prepararon pequeños discos de hojas frescas de higuerilla desinfectadas, de $5 \mathrm{~mm}$ de diámetro, de la parte sana del limbo, sobre el cual se puso, con una micropipeta, $2 \mu 1$ de la suspensión viral a evaluar, agitándose constantemente debido a que los poliedros sedimentan rápidamente. Se dejó secar la suspensión a temperatura ambiente, se colocaron las larvas y se taparon las placas petri. La evaluación fue diaria. Se descartó aquellas larvas que no consumieron el material tratado. Posteriormente, se les alimentó con hojas frescas de "higuerilla". Para determinar el Tiempo Letal Medio $\left(\mathrm{TL}_{50}\right)$, los datos se registraron aproximadamente durante 15 días después de la infectación, período en que las larvas de los tratamientos que no morían alcanzaban a empupar. Para determinar la causa de la mortalidad se examinó, en el microscopio fotónico, la hemolinfa de las larvas muertas y sólo se consideró a las que murieron por acción del virus.

\section{Estimación del número promedio de cuerpos de inclusión (CI) producidos en larvas infectadas}

Se procedió a separar en un tubo de ensayo 80 larvas del $5^{\text {to }}$ estadío y en otro tubo otras 80 larvas del $6^{\text {to }}$ estadío, de forma independiente, luego se trituró y homogenizó las larvas muertas, con ayuda de una micropipeta de $100 \mathrm{ml}$ se realizó las diluciones y en la cámara de Neubauer se determinó la cantidad promedio de cuerpos de inclusión por larva. 


\section{Análisis estadístico}

En el análisis estadístico se utilizó la mortalidad corregida por la fórmula de Abbott (WHO, 1975).

$$
P c=\frac{(P o-P t x 100)}{100-P t}
$$

Donde:

$\mathrm{Pc}=$ Porcentaje de mortalidad corregida.

Po $=$ Porcentaje de mortalidad observada.

$\mathrm{Pt}=$ Porcentaje de mortalidad en el testigo.

En las pruebas de mortalidad para el análisis de varianza, así como la prueba de significancia de Bonferonni del Tiempo Letal Medio $\left(\mathrm{TL}_{50}\right)$ para las larvas del $3^{\text {er }}$ estadío, los datos originales del número de larvas muertas se homogenizaron por extrapolación; estos análisis se determinaron utilizando el programa estadístico SAS System, en versión 8.0. El cálculo de la regresión dosis-mortalidad, así como los estimados de los límites de confianza, se realizaron de acuerdo al análisis Probit, usando los programas MSTATC y ANALYSE de la dosis letal media $\left(\mathrm{DL}_{50}\right)$, en versión 4.3 .

\section{RESULTADOS}

\section{Identificación del virus}

Fue identificado como un Virus de Poliedrosis Nuclear (Genoma de los Poliedrovirus; familia de los Baculoviridae. (Murphy et al., 1995), sobre larvas del "cogollero del maíz" Spodoptera frugiperda, bautizado como SfVPN (Zeddam, 1998), constituyéndose en el primer reporte para la Amazonía peruana. 


\section{Multiplicación del SfVPN}

Se observaron síntomas de la enfermedad en las larvas sometidas al experimento, con inapetencia desde el segundo día de la infección. Posteriormente, se presentó pérdida de movimiento, disminución de la tasa de alimentación y su coloración se hizo más clara, adquiriendo un color marrón oscuro al final de la enfermedad. Las larvas muertas quedaban adheridas, con sus seudopatas, a las hojas de higuerillas y las que morían en la parte superior del envase, se adherían a la tapa del recipiente e inclinaban su cabeza hacia abajo. Después de su muerte se procedió a su recolección. Pasadas las 24 horas, su epitelio se tornaba frágil y se rompía con facilidad, liberando un líquido lechoso (Figura 1), siendo difícil recolectarlas completas. Al observar este líquido lechoso (hemolinfa) al microscopio fotónico se comprobó la presencia de millares de cuerpos de inclusión de los virus (Figura 2).

\section{Análisis de los datos de la mortalidad después de la infección}

\section{Determinación de la dosis letal medía $\mathrm{DL}_{50}$.}

La Tabla 1 muestra las diferentes cantidades de cuerpos de inclusión de SfVPN utilizados en cada dosis, la mortalidad observada en larvas y la mortalidad en el testigo para calcular, utilizando la fórmula de Abbott para el cálculo de la mortalidad corregida. Se observa que a medida que aumenta la concentración de las dosis las mortalidades también se incrementan en cada dosis evaluada, alcanzándose en la dosis sexta (6' 400 000) un 100\% de mortalidad.

Tabla 1. Mortalidad de larvas de $3^{\text {er }}$ estadío del "cogollero del maíz" Spodoptera frugiperda infectadas con diferentes dosis del SfVPN, en condiciones de laboratorio. Iquitos 1999.

\begin{tabular}{|c|c|c|c|c|}
\hline $\begin{array}{c}\text { Dosis } \\
\text { (CI/larva) }\end{array}$ & $\begin{array}{c}\mathbf{N}^{\mathbf{0}} \text { de Larvas } \\
\text { Evaluadas }\end{array}$ & $\begin{array}{c}\mathbf{N}^{\mathbf{0}} \text { de Larvas } \\
\text { muertas con } \\
\text { SfVPN }\end{array}$ & $\begin{array}{c}\text { Mortalidad en } \\
\text { el Testigo }\end{array}$ & $\begin{array}{c}\text { \% de } \\
\text { Mortalidad } \\
\text { Corregida }\end{array}$ \\
\hline 64 & 28 & 3 & 0 & 11 \\
\hline 640 & 30 & 4 & 2 & 7 \\
\hline 6400 & 27 & 5 & 3 & 9 \\
\hline 64000 & 29 & 9 & 2 & 26 \\
\hline 640000 & 28 & 24 & 3 & 84 \\
\hline 6 '400 000 & 30 & 30 & 4 & 100 \\
\hline
\end{tabular}


El programa Probit no considera los ensayos con 0 ó $100 \%$ de mortalidad, por lo que sólo se consideran cinco ensayos en la regresión lineal Dosis-Mortalidad (Figura 1). La ecuación $\mathrm{Y}=1.91391+(0.65718 \mathrm{X})$, se usa para determinar una $\mathrm{DL}_{50}$ de 49,653 poliedros por larva (Tabla 2).

Figura 1. Línea de Regresión dosis-mortalidad para larvas del cogollero del maíz Spodoptera frugiperda infectadas con SfVPN

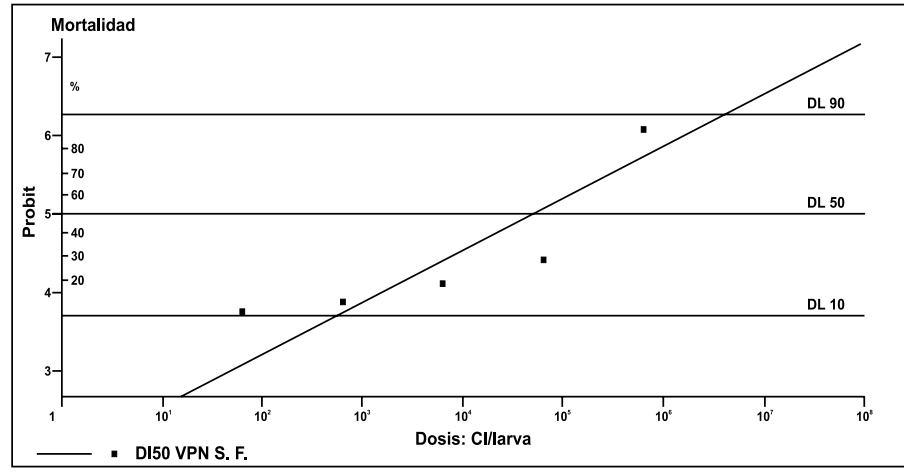

Tabla 2. Resultados del análisis Probit determinando las $\mathrm{DL}_{10}, \mathrm{DL}_{50} \mathrm{y} \mathrm{DL}_{90}$ del SfVPN sobre larvas del "cogollero del maíz" Spodoptera frugiperda. Iquitos 1999.

\begin{tabular}{|c|c|c|c|}
\hline Dosis Letal (CI/larva) & Dosis (CI/Larva) & Límite Inferior & Límite Superior \\
\hline $\mathrm{DL}_{90}$ & 4426855 & 1061642 & 18459181 \\
\hline $\mathrm{DL}_{50}$ & 49653 & 22107 & 111521 \\
\hline $\mathrm{DL}_{10}$ & 556 & 148 & 2088 \\
\hline
\end{tabular}

En la Tabla 2 se muestra el valor de la $\mathrm{DL}_{50}$ con sus respectivos intervalos de confianza; se incluye, además, los datos acerca de la $\mathrm{DL}_{90}$ y $\mathrm{DL}_{10}$.

\section{Tiempo Letal Medio $\left(\mathrm{TL}_{50}\right)$}

En la Tabla 3, se muestra el análisis de varianza del tiempo letal medio (días) de las larvas del $3^{\text {er }}$ estadío del "cogollero del maíz" Spodoptera frugiperda infectadas con diferentes dosis del virus SfVPN, la misma que expresa diferencia significativa $(\mathrm{P}=0.05$ y $\mathrm{Fc}=120.49$ y $\mathrm{Ft}=1.35)$ para la fuente de variación del tratamiento. 
Tabla 3. Análisis de varianza del tiempo letal medio (días) de larvas del $3^{\text {er }}$ estadío del "cogollero del maíz" Spodoptera frugiperda infectadas con diferentes dosis del virus SfVPN.

\begin{tabular}{|c|c|c|c|c|c|}
\hline F. de V. & G.L & S.C & C.M & Fc & Ft (0.05) \\
\hline Tratamientos & 89 & 1310.64 & 14.73 & $120.49^{* *}$ & 1.35 \\
Error & 90 & 11 & 0.12 & & \\
Total & 179 & 1321.64 & & & \\
\hline
\end{tabular}

Leyenda: $\quad$ F. de V.: Fuente de Variación; G.L.: Grados de Libertad; S.C.: Suma de Cuadrados; C.M.: Cuadrado Medio; Fc: F Calculado; Ft: F Tabulado.

Tabla 4. Prueba de significación de Bonferroni del tiempo letal medio (días) de larvas del $3^{\text {er }}$ estadío del "cogollero del maíz" Spodoptera frugiperda infectadas con diferentes dosis del virus SfVPN.

\begin{tabular}{|c|c|c|}
\hline Día & Promedio de muertos & Significación \\
\hline 6 & 6.42 & $\mathrm{~A}$ \\
7 & 5.08 & $\mathrm{~B}$ \\
5 & 0.75 & $\mathrm{C}$ \\
8 & 0.17 & $\mathrm{D}$ \\
11 & 0.17 & $\mathrm{D}$ \\
10 & 0.08 & $\mathrm{D}$ \\
\hline
\end{tabular}

La Tabla 4 muestra la discrepancia estadística en el cuál la máxima mortalidad ocurrió el sexto día con un promedio de 6.42 muertos (significación A), seguido del séptimo día con promedio de 5.08 muertos (significación $\mathrm{B}$ ), además también hubo significancia $(\mathrm{C})$ al quinto día con un promedio de 0.75 muertos, siendo esto superior a los demás días en las que hubo mortalidad (significación D). 
Figura 2. Tiempo Letal Medio (días) de larvas del $3^{\text {er }}$ estadío del "cogollero del maíz" Spodoptera frugiperda infectadas con diferentes dosis de SfVPN
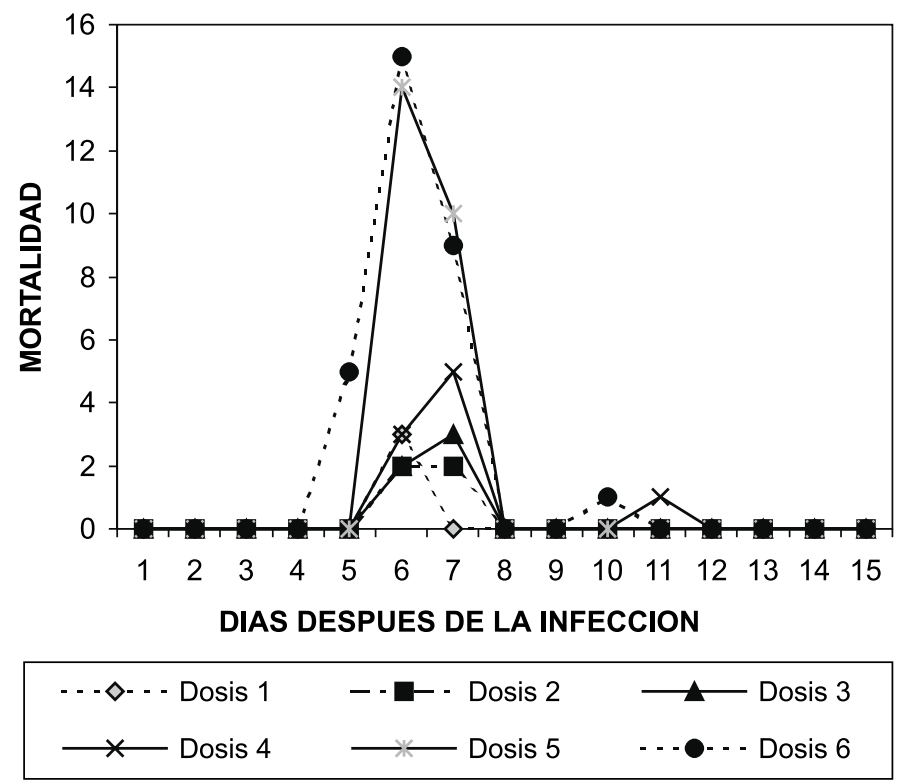

La Figura 2 muestra el tiempo en días que las larvas del $3^{\text {er }}$ estadío del "cogollero del maíz" Spodoptera frugiperda tardan en morir después de ingerir el virus. Se aprecia que la mortalidad comienza a partir del quinto día de la infección y en los días 6 y 7 ocurre la máxima mortalidad entre todas las dosis. Se observa, además, que en las dosis 5 y 6 existe las mayores mortalidades en comparación con las demás dosis.

\section{Determinación del número promedio de cuerpos de inclusión por larva}

La Tabla 5 muestra la cantidad promedio de poliedros que contienen las larvas del $5^{\text {to }}$ y $6^{\text {to }}$ estadío. Aunque la larva de mayor estadío contiene la mayor cantidad de cuerpos de inclusión, su rango no es muy amplio con respecto a la de $5^{\text {to }}$ estadío, siendo las larvas de $5^{\text {to }}$ y $6^{\text {to }}$ estadío buenas productoras del SfVPN a efecto de ser utilizadas en formulaciones de insecticidas biológicos. 
Tabla 5. Estimación del número promedio de cuerpos de inclusión (CI) de SfVPN por larva de $5^{\text {to }}$ y $6^{\text {to }}$ estadío del "cogollero del maíz" Spodoptera frugiperda. Iquitos 1999.

\begin{tabular}{|c|c|c|}
\hline Especie & Estadío & $\begin{array}{c}\text { Promedio de cuerpos de } \\
\text { inclusión por larva }\end{array}$ \\
\hline Spodoptera frugiperda & Larva V & $5.4 \times 10^{8}$ \\
\hline Spodoptera frugiperda & Larva VI & $7.3 \times 10^{8}$ \\
\hline
\end{tabular}

\section{DISCUSIÓN}

Durante el estudio, el Virus de Poliedrosis Nuclear (SfVPN) aislado de larvas del cogollero del maíz, ha demostrado ser un patógeno muy eficiente para provocar alta mortalidad en las poblaciones larvales de este insecto. En todas las infecciones realizadas para su multiplicación se obtuvo una mortalidad de $100 \%$. Estos resultados son similares a los informes de Luna (1996), quien estudió un VPN del "gusano ejército" Spodoptera eridania, y son parecidos a los encontrados por Valicente y Cruz (1991), quienes estudiaron un VPN del "cogollero del maíz" Spodoptera frugiperda, con una mortalidad mayor de $96 \%$.

La infección se realizó en larvas del $3^{\text {er }}$ estadío, que es un método estandarizado que permite comparaciones con los trabajos de otros autores (Valicente y Cruz, 1991). Las larvas en esta edad son lo suficientemente grandes como para ser manipuladas, sin implicar significativo riesgo de mortalidad por esta causa. Sin embargo, el virus podrá actuar antes de la pupación del insecto (Luna, 1996).

El tiempo letal medio es parecido al Virus de Poliedrosis Nuclear brasilero, aislado de una larva del cogollero del maíz encontrado en la Región de Sete Lagoas MG, Brasil; cuyos estudios indican un periodo letal promedio de 5 a 7 días después que la larva ingiere el virus (Valicente y Cruz, 1991).

Tal ocurrencia se da de manera muy parecida al virus empleado por Luna (1996), que indica que el Virus de Poliedrosis Nuclear (SpocVPN) es capaz de matar a larvas del $3^{\text {er }}$ estadío del "gusano ejército", en un periodo de 6 a 8 días. Los síntomas que mostraron las larvas sometidas a los tratamientos han sido típicos a los que producen las enfermedades vírales por VPN (pérdida de movimiento, pérdida de apetito, cambio de coloración, inclinación de la cabeza al morir y ruptura del tegumento), tal como lo indican Cisneros (1995) y Luna (1996). 
Los resultados obtenidos de la $\mathrm{DL}_{50}$ son más elevados que los encontrados por Klein y Podoler (1978), que indican una $\mathrm{DL}_{50}$ de $25800 \mathrm{CI} /$ larva, para larvas de $3^{\text {er }}$ estadío del "gusano ejército", siendo la dosis empleada más elevada en comparación con la utilizada por Valicente y Cruz (1991), quienes obtuvieron una mortalidad de $96 \%$ en larvas de 6 días de edad ( $3^{\text {er }}$ estadío) del "cogollero del maíz" con una dosificación de $4 \times 10^{5} \mathrm{CI} /$ larva. El detalle por la que la $\mathrm{DL}_{50}$ encontrada fuera más elevada que los informados por estos autores sería debido al sustrato usado para su alimentación, ya que podría existir una variabilidad significativa con el alimento que comían las larvas durante los experimentos, tal como lo señalan Keating et al., (1988), los cuales precisan que el contenido de taninos hidrolizables y el $\mathrm{pH}$ de los tejidos de la hojas de la planta hospedera tienen mucha influencia sobre la mortalidad, tal es el caso que en una misma dosis de patógeno determinaron que la mortalidad aumentó cuando disminuyeron la acidez y el contenido de taninos.

De igual modo Santiago y Ortiz (1992), al infectar larvas de $3^{\text {er }}$ estadío del "gusano egipcio del algodón” Spodoptera littoralis, encontraron una $\mathrm{DL}_{50}$ de 20,483 CI/larva, utilizando como alimento el fréjol, sin embargo, al usar papa la $\mathrm{DL}_{50}$ disminuyó considerablemente a 7530 para larvas de la misma especie y edad. En cambio, Luna (1996) encontró una $\mathrm{DL}_{50}$ de $80225 \mathrm{CI} /$ larva para larvas del $3^{\text {er }}$ estadío del "gusano ejército", quien también utilizó como sustrato de alimentación la "higuerilla" Ricinus comunis. Es posible que el VPN empleado sea de otra especie tal como el autor lo precisa.

Es importante indicar que en nuestro caso, el "cogollero del maíz" Spodoptera frugiperda es un polífago, siendo el maíz su planta hospedera principal, es probable que utilizando este sustrato como alimento, $\mathrm{la}_{\mathrm{DL}}$ sería menor. El número promedio de cuerpos de inclusión por larva de $5^{\text {to }}$ y $6^{\text {to }}$ estadío no es muy amplio en comparación con los encontrados por Santiago Álvarez et al., (1994), los cuales indican para el "gusano de tierra" Agrotis segetum una cantidad de $2.64 \times 10^{10} \mathrm{CI} /$ larva en larvas de $4^{\text {to }}$ estadío y $7.15 \times 10^{10}$ para larvas de $5^{\text {to }}$ estadío.

Sin embargo, estos resultados son similares a los encontrados por Luna (1996), quien informa una cantidad promedio de $5.2 \times 10^{7} \mathrm{CI} /$ larva en larvas de $5^{\text {to }}$ y para $6^{\text {to }}$ estadío $7.18 \times 10^{7} \mathrm{CI} /$ larva. 


\section{AGRADECIMIENTO}

Al Dr. Guy Couturier (IRD-Francia) y al Dr. Jeff Ryan (WALTER REED ARMY INSTITUTE RESEARCH-USA) por el financiamiento del presente trabajo de investigación, al Ing. Luis Valdivieso, Blga M. Sc. Elizabeth Núñez e Ing. Hilda Gomez del Centro de Control Biológico (CCB-SENASA) por el apoyo brindado, al Dr. Luis Mori del Departamento de Hidrobiología (FCB-UNAP) por las tomas fotográficas, y especialmente a la Dra. Amy Morrinson (University of CaliforniaAT DAVIS) por los comentarios realizados en el artículo y por todo el apoyo logístico prestado en el presente trabajo.

\section{BIBLIOGRAFÍA}

ALVES, S. 1986. Controle microbiano de insetos. Ed. Manole Ltda. Brasil. 407 pp.

AGRONOTICIAS. 1997. No descuidar la producción. Revista para el desarrollo. Edición No. 213. 90 pp.

CENTRO DE CONTROL BIOLÓGICO, 1995. Crianza artificial de Spodoptera frugiperda. Guía práctica de capacitación. Lima -Perú. 4 pp.

CISNEROS, F. 1995. Control de plagas agrícolas. Lima. Perú. 313 pp.

HERRERA, A. J. 1979. Principales Plagas del Maíz. Boletín Especial de la Dirección de Agricultura y Ganadería del Perú. 10 pp.

KEATING, S.; YENDAL, W.; SCHULTZ, J. C. 1988. Relationship between susceptibility of gypsy moth larvae (Lep.: Lymantriidae) to a baculovirus and host plant foliage constituents. Environm. Entomol. 17 (6): 952 - 958.

KLEIN, M.; PODOLER, H. 1978. Studies on the application of a nuclear polyhedrosis virus to control populations of the Egyptian cottonworm, Spodoptera littoralis. J. Invertebr. Pathol. 32: $244-248$.

LUNA, J. 1996. Caracterización de un virus de poliedrosis nuclear (VPN) sobre larvas de Spodoptera eridanea Cramer y Spodoptera ochrea Hampson, en camote, tesis para optarr el titulo de Ingeniero Agronómo, Lima - La Molina. $120 \mathrm{pp}$. 
MURPHY, F. A.; FAUQUET, C. M.; BISHOP, D. H. L.; GHABRIAL, S. A.; MARTELLI, G. P.; MAYO, M. A.; SUMMERS, M. D. 1995. Sixth Report of the International Committee on Taxonomy of Viruses (eds) Archives of Virology/Supplement 10. Springer Verlag. New York. 586 pp.

SANTIAGO-ALVAREZ, B. C.; ORTIZ-GARCIA, R. 1992. The influence of host plant on the susceptibility of Spodoptera littoralis (Boisd). (Lep.: Noctuidae) larvae to Spodoptera littoralis NPV (Baculoviridae: Baculovirus). J. Appl. Ent. 114: $124-130$.

SANTIAGO-ALVAREZ, B. C.; VARGAS-OSUNA, E.; GONZALES, M.; ALDEBIS H. K. 1994. Influencia de sexo de las larvas hospedantes en la producción in vivo de baculovirus. Investigación agraria, producción y protección de vegetales. Fuera de serie $\mathrm{N}^{\circ} 2.26 \mathrm{pp}$.

TODD, E. L.; POOLE, R. W. 1980. Keys and illustrations for the Armyworm Moths of the Noctuid Genus Spodoptera Guenee from the western hemisphere. Annals of the Entomological Society of America. 73: 722-738

VALICENTE, F.; CRUZ, I. 1991. Controle Biológico da Lagarta do Cartucho, Spodoptera frugiperda, com o Baculovirus. Circular Técnica No. 15. EMBRAPA. 20 pp.

VALDIVIESO, L.; NÚÑEZ, E. 1984. Plagas del maíz y sus enemigos naturales. Boletín del Sector Agrario del Perú. 62 pp.

WHO. 1975. Manual on practical entomology in malaria. Parte II. Genova. 191 pp.

ZEDDAM, J. L.; LUNA, J.; CABRERA, J.; VARGAS Z.; GOMEZ, H. 1997. Aislamiento y caracterización de un virus de poliedrosis nuclear patogénico a Spodoptera eridania. Rev. per. Ent. 40: 63-70.

ZUCCHI, R. A.; NETO, S. S.; NAKANO, O. 1993. Guia de identificacão de Pragas Agricolas. Piracicaba, SP: FEALQ 139 pp. 


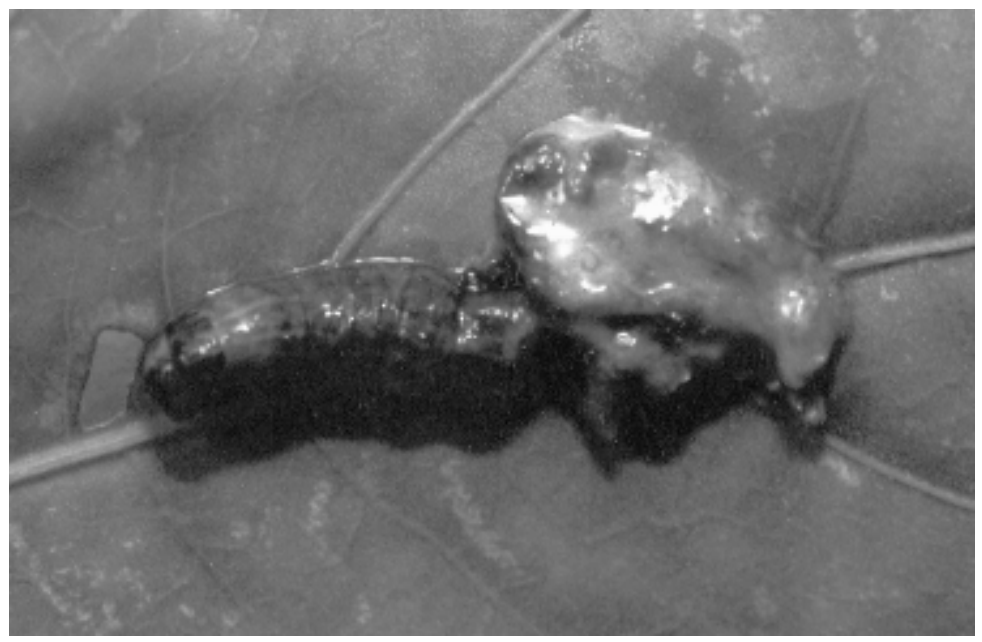

Figura 1. Ruptura de tegumento de una larva muerta del "cogollero del maíz" Spodoptera frugiperda liberando un líquido lechoso.

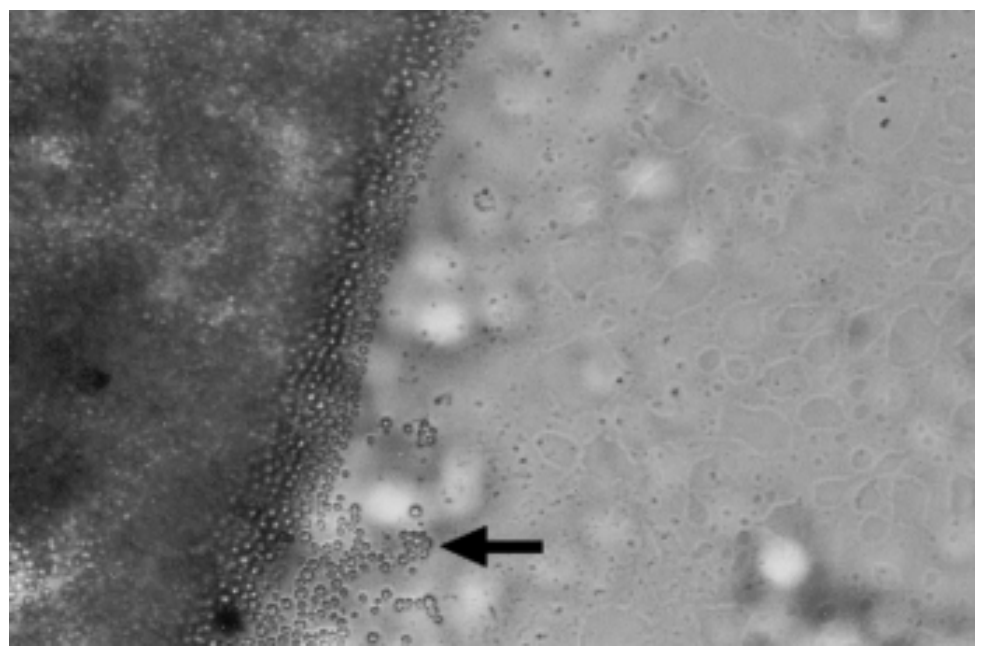

Figura 2. Hemolinfa de una larva muerta por acción del SfVPN observada al microscopio fotónico con 400X de aumento. Se observa millares de cuerpos de inclusión del virus. 